\title{
Silent ischaemia: clinical implications in 1988
}

\author{
K M FOX \\ From the National Heart Hospital, London
}

Within the past few years the concept of silent ischaemia has become widely known. But silent ischaemia is not a new finding. Paul Wood and his colleagues described the development of electrocardiographic changes during exercise testing in the absence of chest pain and suggested that this could represent latent angina. ${ }^{1}$ In 1974 Stern and Tzivoni described asymptomatic alteration in the ST segment recorded during ambulatory monitoring in patients with coronary artery disease. ${ }^{2}$ Subsequent studies showed that such ST segment changes were common. ${ }^{34}$ Initially, concern that these ST segment changes represented a "false positive" response was fuelled by the debate over the use and value of exercise testing as a diagnostic tool..$^{56}$

Later, invasive monitoring in the catheter laboratory, positron tomography, and ambulatory pulmonary artery monitoring showed that most of these episodes of ST segment depression reflect myocardial ischaemia, ${ }^{7-9}$ and it has been proposed that routine clinical management of patients with angina pectoris should include the identification and treatment of silent ischaemia. In the United Kingdom, however, routine ambulatory monitoring to detect and treat silent ischaemia is seldom performed.

It has been suggested that about $60-80 \%$ of patients with chronic stable angina have silent ischaemia. ${ }^{310}$ Unfortunately, most of these data were obtained from highly selected patient populations. Recently we studied 150 unselected patients with angina pectoris on no medical treatment. ${ }^{11}$ Silent episodes of ST segment depression were about three times as frequent as angina pectoris: one third of the patients had both silent episodes and painful episodes of ST segment depression and $20 \%$ had silent episodes without angina pectoris. Also, about a third of the patients had $90 \%$ of the silent episodes of ST

Requests for reprints to Dr K M Fox, National Heart Hospital, Westmoreland Street, London W1M 8BA. segment depression. So silent ischaemia is most likely to be important in about one third of patients with chronic stable angina; other workers also have come to similar conclusions. ${ }^{12}$

This does not imply that silent ischaemia is unimportant. In the United Kingdom about a million patients have chronic stable angina and so about 300000 would have frequent episodes of silent ischaemia. But these data came from patients with chronic stable angina who were not on medical treatment and who had cardiac catheterisation. Similar studies have not been performed in medically treated patients with stable angina; such patients are likely to have fewer episodes of silent ischaemia.

Workers who compared changes in heart rate with changes in the ST segment during ambulatory monitoring and exercise testing concluded that silent ischaemia is predominantly related to an alteration in coronary blood flow. ${ }^{3713}$ But analysis of the heart rate during silent episodes and painful episodes of ST segment depression during ambulatory monitoring does not support this conclusion. ${ }^{14}$ The 24 hour diurnal distribution of silent and painful ischaemia is similar; in patients with chronic stable angina there are more episodes between 9 am and $10 \mathrm{pm}$ than during the rest of the day and night, ${ }^{315}$ while in patients with variant angina, silent episodes and painful episodes are most common at night. ${ }^{16}$ Analysis of heart rate changes has shown that both silent episodes and painful episodes of ST segment depression can on occasion be preceded by increase in the heart rate while other episodes within the same patient are not. Mental stress can provoke myocardial ischaemia; often this is silent. ${ }^{17}$ The pathophysiological mechanisms for this picture are unclear but an increase in myocardial oxygen demand and coronary vasoconstricion are likely to be important. Thus in chronic stable angina, silent ischaemia could be caused by various mechanisms as is angina pectoris. These mechanisms will vary from patient to 
patient and even from hour to hour within the same patient. The prediction that if the pathophysiological mechanisms of silent ischaemia and angina are similar both conditions will respond to the same treatment is borne out by reports that drugs that relieve angina can also suppress silent ischaemia. ${ }^{18-20}$

Although silent ischaemia can be treated with antianginal agents it is still far from certain that such treatment is necessary or justifies the extra cost and staff it would require. Silent ischaemia is best identified by 24 hour ambulatory monitoring of the electrocardiogram. Amplitude modulated systems give a more stable baseline and are more widely available but frequency modulated systems give a more appropriate frequency response. ${ }^{21}$ The new generation of solid state systems that are now available gives computerised reports and these need little attention from a technician. ${ }^{22}$ Although solid state systems are less labour intensive they require validation and they are expensive.

Must ambulatory monitoring be used to identify silent ischaemia? Perhaps the investigations could be targeted more appropriately? Selwyn and Ganz suggested that angina pectoris does not reflect the true severity of myocardial ischaemia and that ambulatory monitoring may be needed to identify those patients with the worst prognosis. ${ }^{23}$ But in the same issue of the Nerw England Journal of Medicine, Epstein et al claimed that electrocardiographic monitoring added little to the prognostic information provided by exercise testing ${ }^{24}$ Certainly, silent ischaemia is rare in those patients with a negative exercise test and in those whose exercise test is positive only at high workload. ${ }^{112526}$ Also there seems to be a close linear correlation between the time to $1 \mathrm{~mm}$ ST segment depression recorded during exercise testing and the frequency of silent ischaemia; perhaps therefore ambulatory monitoring could be restricted to those patients with ST segment depression at low workloads on the exercise test.

Although silent ischaemia can be treated and the use of exercise testing with ambulatory monitoring might not overstretch resources, we still do not know whether silent ischaemia in patients with chronic stable angina should be identified and treated. Prognostic data are woefully lacking. In the 1970 s Erikssen et al investigated 2014 symptom free male factory workers by exercise testing and coronary angiography. ${ }^{27}$ Fifty men had a positive exercise test and confirmed coronary artery disease without chest pain. In the next eight years $10(20 \%)$ developed an acute myocardial infarction or died. But it is still not certain that these subsequent cardiovascular events had anything to do with silent ischaemia; they may have merely reflected the underlying coronary artery disease. More importantly, would treatment of silent ischaemia have prevented these events? Acute myocardial infarction is usually caused by rupture of an atherosclerotic plaque and the same mechanism almost certainly causes sudden death. ${ }^{23}$ What effect will antianginal agents have? At the present time there is no evidence to suggest that preventing ischaemic episodes either by reduction of myocardial oxygen demand or by increasing coronary blood flow will have any effect on plaque rupture and thrombosis. Perhaps the frequency of silent ischaemia together with a diminution of exercise tolerance are markers that a stable plaque has become unstable; in such circumstances it might be better to stabilise the plaque and thrombotic process with drugs that prevent surges in blood pressure, smooth muscle relaxants, antithrombotic and anti-platelet agents, or to operate or perform angioplasty.

Another suggestion is that repeated episodes of myocardial ischaemia lead to small areas of myocardial cell death and subsequent reduction of left ventricular function. ${ }^{29}$ If this is true, drugs that reduce the frequency and duration of silent ischaemic insults may be beneficial. Preliminary data support this theory ${ }^{30}$ but further studies are needed to resolve the question.

In contrast, in unstable angina evidence suggests that episodes of painful and silent ischaemia do have important prognostic implications. Gottlieb and his co-workers showed that silent ischaemia in patients with unstable angina was associated with an increased number of cardiovascullar events, particularly myocardial infarction and death. ${ }^{31}$ The most likely mechanism for the angina that precedes infarction is an unstable plaque with superadded platelet aggregation and possibly thrombosis. ${ }^{28}$ Appropriate treatment of such ischaemia may prove rewarding. Again, however, although drugs that reduce myocardial oxygen demand and smooth muscle relaxants permit the myocardium to withstand greater ischaemic insults, they are unlikely to prevent myocardial infarction. In the recent Holland Interuniversity Nifedipine/Metoprolol trial the risk ratio of preventing acute myocardial infarction with $\beta$ blocker alone was 1.07 and that for calcium antagonist was $1.51{ }^{32}$ The use of drugs or interventions that directly influence the pathogenesis may, therefore, have to be considered-such as antiplatelet agents, coronary angioplasty, and bypass surgery. ${ }^{33}$ Most clinicians would probably consider exercise testing unwise in patients with unstable angina, and repeated ambulatory monitoring to assess the frequency, duration and severity of silent and painful ischaemia may well prove to be the most suitable investigation.

Silent ischaemia may be an important feature for identifying patients who will require further investigation and careful consideration of treatment. But 
much of this is speculation and until firm data have been collected routine ambulatory monitoring of the ST segment cannot be advised. In the United States there are devices ( $Q$ Med) to monitor the ST segment; ST segment depression sets off an alarm that prompts the patient to take a tablet of glyceryl trinitrate..$^{22}$ The barometer of silent ischaemia has yet to settle; I hope that it will not be at this extreme.

\section{References}

1 Wood P, McGregor M, Magidson O, Whittaker W. The effort test in angina pectoris. $\mathrm{Br}$ Heart $J$ 1950;12:363-71.

2 Stern S, Tzivoni D. Early detection of silent ischaemic heart disease by 24-hour electrocardiographic monitoring of active subjects. Br Heart $J$ 1974;36:481-6.

3 Deanfield JE, Maseri A, Selwyn AP, et al. Myocardial ischemia during daily life in patients with stable angina: its relation to symptoms and heart rate changes. Lancet 1983;ii:753-8.

4 Quyyumi AA, Wright CM, Mockus LJ, Fox KM. How important is a history of chest pain in determining the degree of ischaemia in patients with angina pectoris? Br Heart J 1985;54:22-6.

5 Redwood DR, Borer JS, Epstein ES. Whither the ST segment during exercise? Circulation 1976;54:703-6.

6 Borer JS,, Brensihe JF, Levy RI, et al. Limitations of the electrocardiographic response to exercise in predicting coronary artery disease. $N$ Engl J Med 1975;283:367-71.

7 Chierchia S, Lazzari M, Freedman SB, Brunelli C, Maseri A. Impairment of myocardial perfusion and function during painless myocardial ischemia. $\mathrm{J} \mathrm{Am}$ Coll Cardiol 1983;1:924-30.

8 Deanfield JE, Shea ML, Ribeiro, P, et al. Transient ST segment depression as a marker of myocardial ischaemia during daily life. Am J Cardiol 1984; 54:1195-200.

9 Levy RD, Shapiro LM, Wright C, Mockus LJ, Fox $\mathrm{KM}$. The haemodynamic significance of asymptomatic ST segment depression assessed by ambulatory pulmonary artery pressure monitoring. $\mathrm{Br}$ Heart J 1986;56:526-30.

10 Cecci AC, Dovellini EV, Marchi F, et al. Silent myocardial ischemia during ambulatory electrocardiographic monitoring in patients with effort angina. J Am Coll Cardiol 1983;1:934-9.

11 Mulcahy D, Keegan J, Crean P, et al. Silent myocardial ischaemia in chronic stable angina: a study of its frequency and characteristics in 150 patients. Br Heart J 1988;60:417-23.

12 Cohn PF. Silent myocardial ischemia in patients with a defective anginal warning system. Am J Cardiol 1980;45:697-702.

13 Schang SJ, Pepine CJ. Transient asymptomatic ST segment depression during daily activity. Am J Cardiol 1977;39:396-402.

14 Quyyumi AA, Wright CA, Mockus LJ, Fox KM. Mechanisms of nocturnal angina pectoris: importance of increased myocardial oxygen demand in patients with severe coronary artery disease. Lancet 1984; i:1207-9.

15 Rocco MB, Barry J, Cambell S, et al. Circadian variation of transient myocardial ischaemia in patients with coronary artery disease. Circulation 1987;75: 395-400.

16 Chierchia S, Brunelli C, Simonette I, Lazzari M, Maseri A. Sequence of events in angina at rest: primary reduction in coronary flow. Circulation 1980;61:759-68.

17 Rozanski A, Bairey CN, Krantz DS. Mental stress and the induction of silent myocardial ischaemia in patients with coronary artery disease. $N$ Engl J Med 1988;318:1005-12.

18 Quyyumi AA, Wright C, Mockus L, Fox KM. Effect of partial agonist activity in beta blockers in severe angina pectoris: a double blind comparison of pindolol and atenolol. $\mathrm{Br}$ Med J 1984;289:951-3.

19 Quyyumi AA, Wright C, Mockus L, Shackell M, Sutton GC, Fox KM. The effects of combined alpha and beta adrenoreceptor blockade in patients with angina pectoris: a double blind study comparing labetalol with placebo. Br Heart J 1985;53:47-52.

20 Oakley D, Fox KM, Selwyn A, Dargie H. An objective assessment of treatment of severe angina: pilot study using nifedipine, propranolol and their combination. Br Med J 1979;i:1540.

21 Bragg-Remschel DA, Anderson CM, Winkle RA. Frequency response characteristics of ambulatory ECG monitoring systems and their implications for ST segment analysis. Am Heart $J$ 1982;103:20-1.

22 Barry J, Cambell S, Nadel EG, Mead K, Selwyn AP. Ambulatory monitoring of the digitized electrocardiogram for detection and early warning of transient myocardial ischaemia in angina pectoris. $\mathrm{Am} \mathrm{J} \mathrm{Cardiol}$ 1987;60:483-8.

23 Selwyn AP, Ganz P. Myocardial ischemia in coronary disease. N Engl J Med 1988;318:1058-60.

24 Epstein SE, Quyyumi AA, Bonow RO. Myocardial ischemia-silent or symptomatic. $N$ Engl J Med 1988;318:1038-43.

25 Quyyumi AA, Mockus L, Wright C, Fox KM. Morphology of ambulatory ST segment changes in patients with varying severity of coronary artery disease: investigation of the frequency of nocturnal ischaemia and coronary spasm. Br Heart $J$ 1985;53:186-93.

26 Cambell S, Barry J, Rebecca GS, et al. Active transient myocardial ischemia during daily life in symptomatic patients with positive exercise tests and coronary artery disease. Am J Cardiol 1986;57:1010-6.

27 Erikssen J, Cohn PF, Thaulous E, Mowinchel P. Silent myocardial ischaemia in middle aged men: longterm clinical course. In: von Arnim T, Maseri A, eds. Silent ischemia: current concepts and management. Darmstadt: Steinkopff Verlag and New York: Springer Verlag, 1987:45-51.

28 Davies MJ, Thomas AC. Plaque fissuring - the cause of acute myocardial infarction, sudden ischaemic death, and crescendo angina. Br Heart J 1985;53:363-73.

29 Pantely GA, Bristow JD. Ischemic cardiomyopathy. Prog Cardiovasc Dis 1984;27:95-102. 
30 Hess OM, Schneider J, Nonogi H, et al. Myocardial structure in patients with exercise-induced ischemia. Circulation 1988;77:967-77.

31 Gottlieb SO, Weisfeldt ML, Ouyang P, Mellits ED, Gerstenblith $G$. Silent ischaemia as a marker for early unfavourable outcomes in patients with unstable ar zina. $N$ Engl J Med 1986;314:1214-9.

32 The Holland Interuniversity Niifedipine/Metoprolol
Trial (HINT) research group. Early treatment of unstable angina in the coronary care unit: a randomised, double blind, placebo controlled comparison of recurrent ischaemia in patients treated with nifedipine or metoprolol or both. Br Heart $J$ 1986; 56:400-13.

33 Fox KM, Krikler DM. Early treatment of unstable angina. Br Heart J 1986;56:398-9. 